\title{
ENERGY CONSUMPTION OF ROMANIAS' DEVELOPMENT REGIONS
}

\author{
TILICH, D[iana] S[orina]
}

\begin{abstract}
Having the same targets as the European Union, Romania is promoting renewable energy sources so that they meet the increasing demand for energy while traditional sources become limited. This paper proposes the integration of a regional energy concept into the action plan for a sustainable regional development, which will help Romania increase the share of renewable energy in its energy mix. Public institutions and research institutes should be involved in developing the regional energy concept, thus introducing research in the circle of decision making, while setting energy policies with real chances of success. This study reveals the current situation regarding energy consumption and its structure at regional level. The quantification of the present situation in the energy sector at regional level was carried out by considering a variety of sources, such as statistics and research reports. The results revealed by this study represent the first steps in the direction of implementing regional energy concepts for Romania's regional development regions.

Keywords: development region, regional energy concept, renewable energy, Romania
\end{abstract}

\section{INTRODUCTION}

Until a few years ago energy production was conceived as a centralized and standardized system. Introducing the renewable energy sources into the energy mix has raised many issues for this traditional system, such as the fact that they are mostly available in certain areas or that transport is subject to great limitations. In this context, a regional energy concept can make these disadvantages decrease by fulfilling regional energy needs with local resources. A regional energy concept helps identify, classify and prioritize possible and necessary measures for integrating renewable energy in the final energy consumption and ensuring climate protection at regional level.

This study quantifies and structures the current energy consumption at NUTS II level (Nomenclature of territorial units for statistics, second level), namely for Romania's eight development regions, by using statistical data and modeling it for each region. This study does not present any technical potential of renewable energy sources for these regions, but represents a first step in determining their present energy consumption.

Previous research focuses on social, infrastructure or economical related issues. In one of her studies Zamfir A. [1] analyses the renewable energy potential in Romania's Center development region but does not quantify any energy consumption or potential of the region's renewable energy.
This research contributes substantial to the first stages of a regional energy concept, by defining the present situation, the current energy consumption and its structure for each development region.

The next steps to this analysis include research regarding the local availability and the regional technical potential of renewable energy sources. This will provide basic data for recommendations, measures and projects proposals for Romania's development regions.

This study and the research that will follow shortly, regarding exploitation of renewable and traditional energy sources energy will help authorities to establish policies with real chances of success and invest in areas that can improve regional development.

\section{ROMANIAS' DEVELOPMENT REGIONS}

The development regions represent statistical entities created in 1998 by county councils to coordinate regional development required at the time of accession to the European Union. Their functions are to allocate funds from the EU funds for regional development and interpret and explore regional statistics.

In the present context, in order to develop a regional energy concept, these regions should define their administrative status in order to obtain executive power so that they become able to establish and implement targets set by this type of concept. Romania's development regions are [2]: North-West Region, Central Region, North East Region, South East Region, South Region, Bucharest-Ilfov Region, South West Region and West Region.

\subsection{Energy consumption and its structure}

Considering an average specific consumption for a Romanian dwelling and correlating it to the number of dwellings per region [3], the average energy consumption at NUTS II level is presented in Table 1.

Hoping that these regions will have their own targets or at least endorse the European targets regarding energy efficiency by $20 \%$ over the next 8 years, the desired amounts of the energy to be consumed in 2020 are also revealed by Table 1 .

Estimating the targeted consumption for the year 2020, this study helps regional actors realize the need to change their present behavior while dealing with energy issues and improve actions that support local development and cooperation. 
access with priority, as long as this has no negative impact on the safety of the national energy system.

Figure 3 shows that the electricity and green certificates are sold on separate markets.

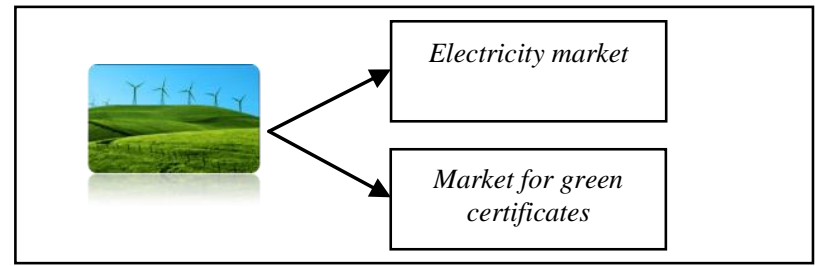

Fig. 3. Promotion system for renewable electricity [6]

In order to analyze in detail various aspects of possible uses of the surface, it would be desirable to have detailed statistical data for the following categories of areas which are directly involved into the design of the regional energy plan:

1. The area occupied by dwellings.

2. The area occupied by industrial buildings, office buildings and other buildings designed for commercial activities.

3. Forest area.

4. Agricultural land.

5. The area occupied by meadows and pastures.

As new technologies use renewable energy sources from the region, the way the surface of that region is used becomes an interesting topic in establishing the regional energy concept. This way an interdisciplinary collaboration with spatial planning specialists becomes very important.

For a better view of the renewable energy potential, especially for decentralized energy production, spatially correlated data is very useful. A geographic information system can present and analyze local landscape, temperatures or information about built area. Data from laser scanning of the areas and images obtained by overflying the studied areas or thermal images can be integrated into the geographic information system and are useful in analyzing the potential for photovoltaic systems, solar system and wind power. Such analyses are important for each region in its attempt to reduce dependence on energy imports or even secure their own energy needs on the way to becoming an energy independent region.

The analysis of all possibilities of a region uses terms that need to be defined and delimited as follows [7]:

a. Theoretical potential is defined as the availability of energy sources in a specific region within a certain period of time, such as for example the solar radiation during a year or the kinetic energy of wind throughout that year.

b. To convert the theoretical potential in practice certain technologies are used. They define the technical potential. The techniques can potentially be improved by further development of the technology in question and is dependent contrary to the theoretical potential by the development stage of the technology.
c.Sustainable potential is considered to be at the intersection of economic potential, environmental and social potential, subject to all aspects of sustainable development.

Since necessary data are not always available to engineers working on such a concept, data from the past which define trends and influence forecasts, can provide the necessary information. Table 4 reviews the types of data with which engineers should work, while developing energy concepts [7]. The data covers all types of energy.

\begin{tabular}{|l|l|l|}
\hline \multirow{2}{*}{$\begin{array}{c}\text { Energy } \\
\text { form }\end{array}$} & \multicolumn{1}{|c|}{$\begin{array}{c}\text { Energy source/ } \\
\text { technology }\end{array}$} & \multicolumn{1}{c|}{ Type of data } \\
\cline { 2 - 3 } Electricity & Water & Water speed in $\mathrm{m}^{3} / \mathrm{s}$ \\
\cline { 2 - 3 } & Wind & Wind speed \\
\cline { 2 - 3 } & $\begin{array}{l}\text { Photovoltaic } \\
\text { systems }\end{array}$ & $\begin{array}{l}\text { Roof surface, free areas, } \\
\text { annual solar radiation }\end{array}$ \\
\hline \multirow{4}{*}{$\begin{array}{l}\text { Thermal } \\
\text { energy }\end{array}$} & Solar systems & $\begin{array}{l}\text { Average annual solar } \\
\text { radiation }\end{array}$ \\
\cline { 2 - 3 } & Biomass & $\begin{array}{l}\text { Tones of crops on available } \\
\text { areas }\end{array}$ \\
\cline { 2 - 3 } & Geothermal & Recommended areas \\
\cline { 2 - 3 } & Residual water & $\begin{array}{l}\text { Diameter of the sewage } \\
\text { channels }\end{array}$ \\
\cline { 2 - 3 } & $\begin{array}{l}\text { Combined heat and } \\
\text { power }\end{array}$ & $\begin{array}{l}\text { Existing plants and their } \\
\text { efficiency }\end{array}$ \\
\hline Fuel & Biodiesel & Quantities on available areas \\
\hline
\end{tabular}

Tab. 2. Necessary data for developing an energy concept [7]

Regional policy is mostly abstract in its nature, seeking to define an ideal a given positive scenario. But in practice a policy must fulfill the following functions:

1. Legitimate actions.

2. Provide guidance for stakeholders.

3. Motivate specific actions.

4. Coordinate regional actors.

Setting objectives comes to complete those areas where the units of measure cannot fully define a desired fact. Policy has no clear temporal separation and should not be affected by progress or further development. It must, however, be consistent and durable enough to offer guidance and motivation necessary in order to facilitate actions and to assist regions that wish to secure energy needs in a sustainable way.

Identification of possible scenarios of evolution serves to define a trend. The types of scenarios that can be taken into account are:

1. "Business as usual" describes the development of current trends.

2. Contrast scenario defines measures needed to be taken to achieve a certain goal, which could not be achieved under current development.

3. Alternative scenario takes into account developments that currently are identifiable but are not dominant.

As an example for a detailed analysis of the various possibilities of uses of the surface the chart below reveals the distribution of types of areas in Romania's Center development region. Graphs were created using statistical data made available by the National Institute of Statistics for the development regions, NUTS II areas that is expected to develop regional energy planes. 
The information includes the area occupied by housing, the area occupied by industrial buildings, office buildings or serving other business, the forests, agricultural land, surface occupied by meadows and pastures.

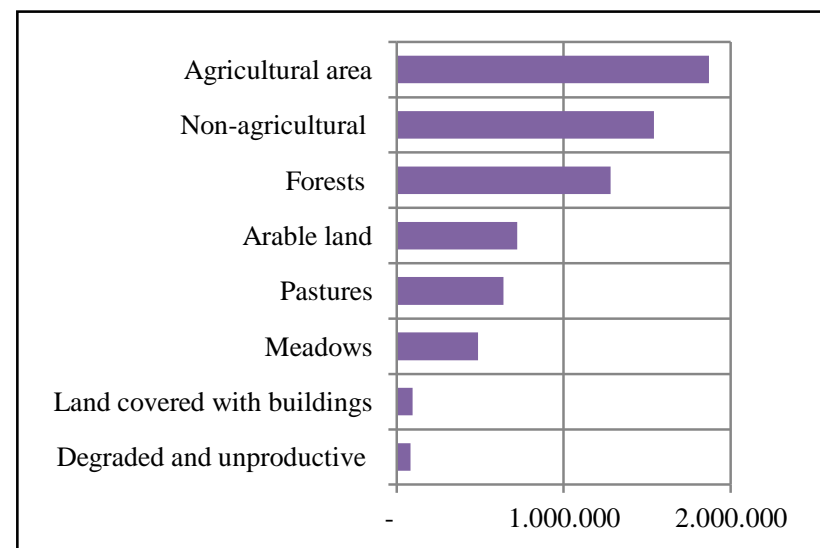

Fig. 4. Land use in Romania's Center development region [3]

\subsection{Conclusions and recommendations for private households}

Because heating and hot water are consumed in a very high amount in a household. Most of the technologies used to produce energy are ineffective. In new and existing homes new energy requirements have to be met (regarding heating, hot water or electricity) in order to reduce energy consumption, but without compromising comfort.

Also it is recommended to use more efficient methods of energy use. These include:

1. Thermal insulation of the dwellings.

2. Correct dimensioning of home heating systems. An installation will cause loss if it is oversized while an undersized one cannot ensure thermal comfort that people want and need.

3. Ensure adequate ventilation of dwellings. Air infiltration should be minimized and controlled through vents or fans.

4. Design of houses. Dwellings should be arranged so that they allow a far greater use of the passive solar energy gain. This new aspect should be considered before placing constructions in residential areas. This way the increased energy efficiency by reducing energy demand becomes reality.

To maximize passive solar gain the design of a house should take into account following recommendations:

1. The main living spaces should be oriented south.

2. Distances between buildings should be at least twice their height [8].

3. Avoid shaded areas.

4. Place constructions such as garages, annexes of the houses next to the north oriented wall.

5. Increase the proportion of glass surfaces that are oriented south.

6. Avoid large flows of air or large ventilated spaces for stairs.
In urban areas, the most appropriate technology to use is probably the technology used to create solar electricity. Because photovoltaic is produced at the point of consumption, losses and costs associated with distribution and supply are eliminated.

The advantage of photovoltaic solar panels in urban areas is the potential to be integrated into existing buildings without the need to arrange extra space, being neutral in terms of space utilization.

Most efficient in terms of costs, however, are solarthermal systems. In residential areas both types of systems are recommended: the direct system where the water is heated as it passes directly through the solar collector or the indirect system, where water is heated by heat transfer in a tank. A liquid circulating through the solar collector gets heated and afterwards transfers the heat to the water stored in the tank.

\section{CONCLUSION}

Final conclusion of this study is that energy efficiency must prevail. Position of housing in the regions must be designed in such a way so that the dwelling will get a maximum contribution of solar radiation, light or protection against wind, reducing this way final energy consumption. This study presents the energy consumption and its structure, land surface by use for the development regions. No other previous research quantified this type of data. Based on this research regional energy concepts for each Romanian regions can be developed. It is important that this type of research establishes a pattern for smaller regions also, while bringing benefits to regional development.

\section{ACKNOWLEDGEMENTS}

The work has been funded by the Sectoral Operational Programme Human Resources Development 2007-2013 of the Romanian Ministry of Labor, Family and Social Protection through the Financial Agreement POSDRU/88/1.5/S/61178.

\section{REFERENCES}

[1] Zamfir, A. (2011). Analysis of renewable energy in Romania's center development region. Theoretical and empirical researches in urban management, Vol.6, No.1, (February 2011) (44-55), ISSN 2065-3913

[2] http://enciclopediaromaniei.ro/, (2012). Development regions, Accesed: 2012-10-03

[3] http://www.insse.ro, (2012). The National Statistics Institute, Tempo Online, Accessed on: 2012-08-05

[4] http://epp.eurostat.ec.europa.eu , (2012). Eurostat, Final energy consumption by households, trades, services, etc., Accessed on: 2012-09-24

[5] Ministry of economy, trade and business environment, (2011). National energy strategy for the period 2007-2020, Updated for the period 2011, 2011-08-20

[6] http://www.opcom.ro, (2012). Romanian power market operator, Accessed on: 2012-05-05

[7] Kucharczak L.; Schäfer S. (2010). Regionale Energie- und Klimaschutzkonzepte als Instrument für die Energiewende, Inhalte, Struktur und Funktionen, Available from: http://www.100-ee.de/index.php?id=215 Accessed $:$ 2012-08-05

[8] Energy saving trust, Renewable energy sources for homes in urban environments, (2005). Available from: http://www.elindsey.gov.uk/ 